Regular paper

\title{
Structure and activity of the Photosystem II manganese-stabilizing protein: role of the conserved disulfide bond
}

\author{
Aaron J. Wyman ${ }^{1,3}$ \& Charles F. Yocum ${ }^{1,2, *}$ \\ ${ }^{1}$ Department of Molecular, Cellular and Developmental Biology, University of Michigan, Ann Arbor, MI \\ 48109-1048, USA; ${ }^{2}$ Department of Chemistry, University of Michigan, Ann Arbor, MI 48109-1048, USA; \\ ${ }^{3}$ Department of Biochemistry, Purdue University, West Lafayette, IN 47906, USA; *Author for correspon- \\ dence (e-mail: cyocum@umich.edu; fax: +1734-647-0884)
}

Received 21 February 2005; accepted in revised form 13 May 2005

Key words: intrinsically disordered protein, manganese-stabilizing protein, oxygen evolution, Photosystem II

\begin{abstract}
The 33-kDa manganese-stabilizing protein (MSP) of Photosystem II (PS II) maintains the functional stability of the Mn cluster in the enzyme's active site. This protein has been shown to possess characteristics similar to those of the intrinsically disordered, or natively unfolded proteins [Lydakis-Simantiris et al. (1999b) Biochemistry 38: 404-414]. Alternately it was proposed that MSP should be classified as a molten globule, based in part on the hypothesis that its lone disulfide bridge is necessary for structural stability and function in solution [Shutova et al. (2000) FEBS Lett. 467: 137-140]. A site-directed mutant MSP (C28A,C51A) that eliminates the disulfide bond reconstitutes $\mathrm{O}_{2}$ evolution activity and binds to MSP-free PS II preparations at wild-type levels [Betts et al. (1996) Biochim. Biophys. Acta 1274: 135-142]. This mutant was further characterized by incubation at $90{ }^{\circ} \mathrm{C}$ to determine the effect of loss of the disulfide bridge on MSP thermostability and solution structure. After heating at $90{ }^{\circ} \mathrm{C}$ for $20 \mathrm{~min}, \mathrm{C} 28 \mathrm{~A}, \mathrm{C} 51 \mathrm{~A}$ MSP was still able to bind to PS II preparations at molar stoichiometries similar to those of WT MSP and reconstitute $\mathrm{O}_{2}$ evolution activity. A fraction of the protein aggregates upon heating, but after resolubilization, it regains the ability to bind to PS II and reconstitute $\mathrm{O}_{2}$ evolution activity. Characterization of the solution structure of C28A,C51A MSP, using CD spectroscopy, UV absorption spectroscopy, and gel filtration chromatography, revealed that the mutant has a more disordered solution structure than WT MSP. The disulfide bond is therefore unnecessary for MSP function and the intrinsically disordered characteristics of MSP are not dependent on its presence. However, the disulfide bond does play a role in the solution structure of MSP in vivo, as evidenced by the lability of a C20S MSP mutation in Synechocystis 6803 [Burnap et al. (1994) Biochemistry 33: 13712-13718].
\end{abstract}

Abbreviations: CD - circular dichroism; Chl - chlorophyll; CP - chloroplast protein; DCBQ - 2,6-dichloro$p$-benzoquinone; EDC - 1-ethyl-3-[3-(dimethylamino)propyl]carbodiimide; EDTA - ethylenediamine tetraacetic acid; FT-IR - Fourier transform infrared; IPTG - isopropyl- $\beta$-D-thiogalactopyranoside; MES 2-(N-morpholino) ethanesulfonic acid; MSP - manganese-stabilizing protein; OEC - $\mathrm{O}_{2}$-evolving complex; PAGE - polyacrylamide gel electrophoresis; PS - photosystem; $p s b O$ - gene encoding precursor MSP; SDS - sodium dodecyl sulfate; SMN - buffer composed of sucrose (0.4 M), MES (50 mM, pH 6.0), NaCl $(10 \mathrm{mM})$ ); SW-PS II - Photosystem II preparation treated with $2 \mathrm{M} \mathrm{NaCl}$ to extract $\mathrm{Ca}^{2+}$ and the 23 and $17 \mathrm{kDa}$ extrinsic polypeptides; USW-PS II - Photosystem II preparation treated with $2 \mathrm{M} \mathrm{NaCl}$ to extract $\mathrm{Ca}^{2+}$ and the 23 and $17 \mathrm{kDa}$ extrinsic polypeptides, followed by incubation with $3.1 \mathrm{M}$ urea and $240 \mathrm{mM}$ $\mathrm{NaCl}$ to remove the manganese-stabilizing protein 


\section{Introduction}

Photosystem II (PS II) is the multisubunit enzyme that catalyzes water oxidation. The site of this reaction, called the $\mathrm{O}_{2}$-evolving complex (OEC), is composed of several intrinsic and extrinsic proteins, a tetranuclear $\mathrm{Mn}$ cluster, and $\mathrm{Ca}^{+2}$ and $\mathrm{Cl}^{-}$ (Debus 1992). Substrate $\mathrm{H}_{2} \mathrm{O}$ is oxidized as the $\mathrm{Mn}$ cluster cycles through five distinct redox states, termed S-states $\left(\mathrm{S}_{n}\right.$, where $\left.n=0-4\right)$ (Kok et al. 1970). The intrinsic proteins of PS II include the reaction center subunits $\mathrm{D} 1$ and $\mathrm{D} 2$, proteins that bind accessory antenna Chl $a$ molecules (CP47 and CP43), the $\alpha$ and $\beta$ subunits of cytochrome $b-559$, and a number of small polypeptides of uncertain function (Ikeuchi and Inoue 1988; Debus 1992). The intrinsic proteins stabilize the OEC by forming a membrane-associated core, which provides binding sites for the $\mathrm{Mn}$ cluster and $\mathrm{Ca}^{+2}$, as well as for the extrinsic proteins that reside on the lumenal side of PS II. In eukaryotes, these proteins are the 17,23 , and $33 \mathrm{kDa}$ polypeptides (Seidler 1996). The 17 and $23 \mathrm{kDa}$ proteins form part of a structure that retains $\mathrm{Cl}^{-}$and $\mathrm{Ca}^{+2}$ ions within the OEC (Ghanotakis et al. 1984; Miyao and Murata 1984). These extrinsic subunits are replaced by cytochrome $c-550$ (PsbV) and a $12 \mathrm{kDa}$ subunit (PsbU) in cyanobacteria (Shen and Inoue 1993; Shen et al. 1998), where crystal structures of three PS II preparations from Thermosynechococcus elongatus (Zouni et al. 2001; Ferreira et al. 2004) and Thermosynechococcus vulcanus (Kamiya and Shen 2003) at resolutions from 3.8 to $3.5 \AA$ are available.

The 33-kDa extrinsic polypeptide, also referred to as manganese-stabilizing protein (MSP), plays a critical role in the structure and function of the OEC. It is required for binding of the 17 and $23 \mathrm{kDa}$ proteins and maintains the stability of the Mn cluster (Ono and Inoue 1983, 1986; Miyao and Murata 1984; Miyao et al. 1987; Bricker 1992; Bricker and Frankel 1998). Two copies of MSP bind to the OEC of eukaryotic photosynthetic organisms ( $\mathrm{Xu}$ and Bricker 1992; Seidler 1996; Popelkova et al. 2002a, b) but the crystal structures of PS II from cyanobacteria contain only one copy of MSP (Zouni et al. 2001; Kamiya and Shen 2003; Ferreira et al. 2004). This difference may be due to the absence in cyanobacterial MSP of a N-terminal amino acid sequence that is present in eukaryotic MSP (Popelkova et al. 2002b). When MSP is removed from the OEC during dark incubations, loss of $\mathrm{Cl}^{-}$and $\mathrm{Ca}^{+2}$ occurs along with destabilization of the Mn cluster; a slow release of two $\mathrm{Mn}$ atoms and loss of $\mathrm{O}_{2}$ evolution activity is observed (Miyao and Murata 1984). Disintegration of the Mn cluster and loss of low levels of $\mathrm{O}_{2}$ evolution activity can be prevented if high, non-physiological concentrations of $\mathrm{Ca}^{2+}$ and $\mathrm{Cl}^{-}$are present (Ono and Inoue 1983, 1986; Miyao and Murata 1984; Miyao et al. 1987; Bricker 1992; Seidler 1996; Bricker and Frankel 1998). A psbO gene encodes the mature lumenal form of MSP as a 247-amino acid polypeptide with a predicted molecular mass of $26.5 \mathrm{kDa}$ (Tyagi et al. 1987). Its primary structure includes a disulfide bridge, conserved among all MSP sequences examined so far, that encloses a loop of 22-24 amino acids (De Las Rivas and Heredia 1999; Motoki et al. 2002).

Manganese-stabilizing protein behaves in solution as if it was an intrinsically disordered or natively unfolded protein (Lydakis-Simantiris et al. 1999b). Proteins of this type share a similar set of unique physical and chemical characteristics. In many cases, they are components of multisubunit complexes that carry out diverse functions, such as protein phosphorylation, ribosomal translation, synapse formation, and maintenance of cytoskeletal structure (Weinreb et al. 1996; Uversky et al. 2000; Dunker et al. 2001; Uversky $2002 a, b)$. Characteristics of intrinsically disordered proteins include thermostability, secondary structures containing large amounts of random coil and turn, and primary amino acid sequences with high ratios of charged to hydrophobic residues. These proteins also possess extended solution structures, as determined by gel filtration chromatography and anomalous mobility on SDSPAGE, and by unusually large Stokes radii $\left(R_{\mathrm{S}}\right)$ and sedimentation coefficient $\left(S_{\mathrm{e}}\right)$ values, and also by very acidic or basic pI values (Weinreb et al. 1996; Uversky et al. 2000; Dunker et al. 2001; Uversky 2002a, b). The secondary structure of WT MSP in solution has been shown to consist of about $50-55 \%$ random coil and turns ( $\mathrm{Xu}$ et al. 1994; Ahmed et al. 1995; Sonoyama et al. 1996; Zhang et al. 1996; Shutova et al. 1997; Hutchison et al. 1998; Lydakis-Simantiris et al. 1999a, b; Motoki et al. 2002; Popelkova et al. 2002a, b) and it is an acidic protein $(\mathrm{pI}=5.2)$ whose estimated molecular mass depends on the technique used for analysis. The calculated molecular mass from the $p s b O$ sequence is $26.5 \mathrm{kDa}$, and a similar value is 
obtained with MALDI-TOF mass spectroscopy (Tyagi et al. 1987; Zubrzycki et al. 1998; Svensson et al. 2002). However, on SDS-PAGE MSP exhibits an apparent molecular mass of $33 \mathrm{kDa}$, and in gel filtration experiments, it produces an estimated molecular mass of 38-41 kDa (Kuwabara and Murata 1979; Tyagi et al. 1987; Betts et al. 1998; Lydakis-Simantiris et al. 1999b; Popelkova et al. 2002a, b, 2003a). The protein has a $R_{\mathrm{s}}$ value of $31 \AA$, and its sedimentation coefficient, determined by analytical ultracentrifugation, is $2.26 \mathrm{~S}$; both values being larger than expected for a protein of its predicted mass (Betts et al. 1998; Zubrzycki et al. 1998). In addition, MSP has calculated axial ratios of 4.2 (from sedimentation experiments (Zubrzycki et al. 1998)) and 4.8 (smallangle X-ray scattering (Svensson et al. 2002)), results that suggest that WT MSP has a prolate ellipsoid shape in solution (Zubrzycki et al. 1998). This may account for part of its unusual behavior in gel filtration experiments, but not for its low content of ordered secondary structure. Hutchison et al. (1998) employed FTIR spectroscopy to show that MSP in solution appears to sample a number of conformational states; more recently, Nowaczyk et al. (2004) used NMR to probe the structure of Thermosynechococcus elongatus MSP and found that the soluble protein consists of both a wellordered core as well as regions of flexibility, features previously associated with intrinsically disordered proteins (Dunker et al. 2001; Uversky 2002a, b). Loll et al. (2005) characterized native and recombinant forms of the same protein using FTIR, and concluded that it was more disordered in solution than was spinach MSP. Finally, although MSP is found in mesophilic and thermophilic organisms, it is unique on account of thermostability, as defined by its resistance to heatinduced denaturation, observed in the spinach protein (Lydakis-Simantiris et al. 1999b).

Recently, it has been proposed that MSP has properties consistent with those of a molten globule, rather than of an intrinsically disordered protein (Shutova et al. 2000). This suggestion was based on several criteria: the presence of secondary structure ( $\alpha$-helices, $\beta$-sheet, turns), a more compact structure than the unfolded state, significant flexibility, absence of a defined tertiary structure, and the predicted existence of a hydrophobic core. Other properties presented to compare intrinsically disordered and molten globule proteins included the number of amino acid residues present in the protein, the ratio of the protein's molecular compactness $\left(R_{\mathrm{S}(\mathrm{MG})}\right)$ to that predicted for the unfolded state $\left(R_{\mathrm{s}(\mathrm{N})}\right)$, the percentage of charged amino acid residues, the presence of near-UV CD features, and the $R_{\mathrm{S}}$ value of the protein. Several of the criteria used to designate a protein as a molten globule (Shutova et al. 2000) are also characteristics of intrinsically disordered proteins (Weinreb et al. 1996; LydakisSimantiris et al. 1999b; Uversky et al. 2000; Uversky 2002a, b). A critical factor used to classify MSP as a molten globule protein was the presence of the disulfide bridge; Shutova et al. (2000) proposed that this covalent bond stabilizes a hydrophobic core made up of $\beta$-sheet structure in MSP, and that this is responsible for the protein's thermostability.

A characterization of the effects of deletion of one or both Cys residues on MSP's function and solution structure (Betts et al. 1996) showed that C28A,C51A MSP could reconstitute $\mathrm{O}_{2}$ evolution activity and bind to USW-PS II at levels similar to that of WT MSP. Although removal of a single Cys (C51A) from MSP did not interfere with MSP binding to USW-PS II or with reconstitution of $\mathrm{O}_{2}$ evolution activity, C51A MSP was unable to stabilize $\mathrm{O}_{2}$ evolution activity under long-term illumination conditions. These results suggest that while the disulfide bridge may have a role in maintaining the solution structure of MSP, it does not have a pronounced effect on the protein's ability to bind to PS II and reconstitute $\mathrm{O}_{2}$ evolution activity. To determine the structural role of the disulfide bond in MSP, and how it might affect the protein's classification as intrinsically disordered or as a molten globule, the C28A,C51A MSP mutant was subjected to further characterization. In the work reported here, we have further characterized the function of MSP's disulfide bridge with respect to the protein's thermostability and ability to reconstitute $\mathrm{O}_{2}$ evolution activity. The secondary and tertiary structure of C28A,C51A MSP was characterized using far-UV $\mathrm{CD}$ and near-UV $\mathrm{CD}$ spectroscopy, UV absorbance spectroscopy, and gel-filtration chromatography to determine how the solution structure of the mutant protein differs from that of WT MSP. Elimination of the disulfide bridge creates additional disorder in MSP's solution structure and causes the protein to bind non-specifically to PS II. However, C28A,C51A MSP retains other properties, including thermostability, attributed to intrinsically disordered proteins. 


\section{Materials and methods \\ Overexpression and purification of recombinant WT MSP and C28A,C51A MSP}

Recombinant WT MSP and C28A,C51A MSP were overexpressed in $E$. coli and inclusion bodies were isolated as previously described (Betts et al. 1994, 1996), with the following modifications: only ampicillin $\left(50 \mu \mathrm{g} \mathrm{ml}^{-1}\right)$ was added to the LB media during overexpression, and IPTG at concentrations of $25-32.5 \mu \mathrm{M}$ was used to induce protein overexpression. Both proteins were solubilized from inclusion bodies as described previously (Betts et al. 1994, 1996), with the following modification: inclusion bodies were incubated overnight at $4{ }^{\circ} \mathrm{C}$ with stirring in $3 \mathrm{M}$ urea, $20 \mathrm{mM}$

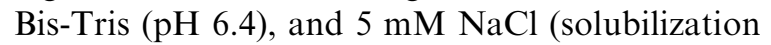
buffer) (Popelkova et al. 2002b, 2003a), The resulting suspension was centrifuged at $48,000 \times g$ for $30 \mathrm{~min}$ at $4{ }^{\circ} \mathrm{C}$, and the supernatant was loaded onto a Pharmacia Resource $\mathrm{Q}$ column equilibrated with solubilization buffer containing 5\% betaine. Proteins were eluted from the column using a linear salt gradient $(5-250 \mathrm{mM} \mathrm{NaCl})$. The MSP's were eluted between 100-200 mM NaCl. The partially purified protein fractions were combined, dialyzed overnight in solubilization buffer minus betaine at $4{ }^{\circ} \mathrm{C}$, and loaded onto the same Resource Q column using solubilization buffer containing $5 \%$ betaine. The second round of ion exchange chromatography utilized a stepwise $\mathrm{NaCl}$ gradient $(30,70,170$, and $1000 \mathrm{mM} \mathrm{NaCl}$ ); MSP eluted at $170 \mathrm{mM} \mathrm{NaCl}$. In order to prevent MSP from aggregating when frozen $\left(-70^{\circ} \mathrm{C}\right)$, the purified proteins were either stored in solubilization buffer, or were dialyzed overnight at $4{ }^{\circ} \mathrm{C}$ in $0.4 \mathrm{M}$ sucrose, $50 \mathrm{mM}$ MES (pH 6.0), and $10 \mathrm{mM}$ $\mathrm{NaCl}$ (SMN); both solutions were found to prevent protein aggregation upon freezing. The protein concentration was determined spectrophotometrically at $276 \mathrm{~nm}$ using an extinction coefficient of $16 \mathrm{mM}^{-1}$ (Xu and Bricker 1992).

\section{PS II membranes: preparation and extraction of extrinsic polypeptides}

PS II membranes were isolated as described in Berthold et al. (1981) with modifications (Ghanotakis et al. 1984). Extrinsic proteins were removed sequentially; the 17 and $23 \mathrm{kDa}$ proteins were extracted first by incubation in $2 \mathrm{M} \mathrm{NaCl}, 1 \mathrm{mM}$ EDTA, and $50 \mathrm{mM}$ MES (pH 6.0) to yield a SWSII preparation. Natively bound MSP was then removed from SW-PS II preparations by a $30 \mathrm{~min}$ incubation in the dark, on ice, in $50 \mathrm{mM}$ MES $(\mathrm{pH}$ 6.0), 3.1 M urea, and $240 \mathrm{mM} \mathrm{NaCl}$ to produce USW-PS II samples (Betts et al. 1994). These samples were washed in SMN-200 buffer (0.4 M sucrose, $50 \mathrm{mM}$ MES (pH 6.0), and $200 \mathrm{mM} \mathrm{NaCl}$ ) prior to suspension in SMN-200 and storage at $-70{ }^{\circ} \mathrm{C}$. Activities for the intact PS II preparations were $600-700 \mu \mathrm{mol}$ of $\mathrm{O}_{2}(\mathrm{mg} \text { of } \mathrm{Chl})^{-1} \mathrm{~h}^{-1}$, for SW-PS II preparations, $300-400 \mu \mathrm{mol}$ of $\mathrm{O}_{2}(\mathrm{mg}$ of $\mathrm{Chl})^{-1} \mathrm{~h}^{-1}$, and for USW-PS II samples, 80-150 $\mu \mathrm{mol}$ of $\mathrm{O}_{2}(\mathrm{mg} \text { of } \mathrm{Chl})^{-1} \mathrm{~h}^{-1}$.

\section{Reconstitution of PS II with WT or C28A,C51A} MSP

Reconstitutions and $\mathrm{O}_{2}$ evolution assays were carried out as previously described (Popelkova et al. 2002a, b, 2003a) with the following modifications: assays of control $\mathrm{O}_{2}$ evolution rates in SW-PS II samples used $300 \mu \mathrm{M}$ DCBQ, while for determination of the recombinant MSP-reconstituted PS II activities, $600 \mu \mathrm{M}$ DCBQ was added. WT MSP and C28A,C51A MSP samples stored in solubilization buffer were dialyzed overnight at $4{ }^{\circ} \mathrm{C}$ against SMN buffer prior to use in reconstitution reactions. Solutions of WT MSP and C28A,C51A MSP both aggregated upon heating at $90^{\circ} \mathrm{C}$ and cooling to $25^{\circ} \mathrm{C}$ (Wyman and Yocum 2005). Heat-treated proteins were centrifuged for $10 \mathrm{~min}$ at $12,000 \times g$ to remove all aggregated, insoluble proteins, which amounted to about $50 \%$ of the total protein present in the sample before heating. The concentration of soluble MSP in the supernatant fraction was determined spectrophotometrically, and this protein was then used in PS II reconstitution experiments. Heat-aggregated MSP was resolubilized from centrifuged pellets by dialyzing the insoluble protein overnight at $4{ }^{\circ} \mathrm{C}$ against $50 \mathrm{mM}$ MES (pH 6.0), $10 \mathrm{mM} \mathrm{NaCl}$, and $3 \mathrm{M}$ urea. The protein was then dialyzed overnight a second time against SMN buffer to remove urea. The concentration of the resolubilized protein was determined as described above.

Reconstitution of USW-PS II with WT MSP and C28A,C51A MSP, and analysis of the extent of rebinding to PS II, were carried out as described 
in Betts et al. (1996) and Popelkova et al. (2003a). The relative concentrations of MSP bound to PS II were determined by integration of Coomassie-stained MSP bands after SDS-PAGE using Sigmagel software (Jandel Scientific). The intensity of the MSP band present in a SW-PS II sample was used as the $100 \%$ MSP control. All staining intensities were normalized to the Coomassiestained $47 \mathrm{kDa}$ band (CP47) to correct for variations that arise from loading protein samples onto the gel. The $\mathrm{O}_{2}$ evolution activity and MSP rebinding data represent the average of 3-6 assays for each point on the graphs.

Circular dichroism spectroscopy, UV absorbance spectroscopy, and size-exclusion chromatography

Solutions of C28A,C51A MSP were dialyzed overnight against $10 \mathrm{mM} \mathrm{KH}_{2} \mathrm{PO}_{4}(\mathrm{pH}$ 6.0) buffer for far-UV $\mathrm{CD}$ and near-UV CD spectroscopy carried out using an AVIV 62 DS CD spectrometer calibrated with $(+) 10$-camphorsulfonic acid (1 $\mathrm{mg} \mathrm{ml}^{-1}$ in $\mathrm{H}_{2} \mathrm{O}$ ) (Johnson 1990). Experimental conditions for the far-UV and near-UV CD spectral measurements are given in the legends for Figure 3 and Figure 4. The secondary structural contents of C28A,C51A MSP from its far-UV CD spectra were estimated using the CONTIN/LL and CDSSTR programs from the CDPro package (Sreerama and Woody 2000) available for downloading from the Internet (http://lamar.colostate.edu/ sreeram/ CDPro). UV spectra were obtained using an OLISmodified Cary-17 instrument. Experimental conditions for the UV spectra are given in the legend of Figure 5. A superose-12 column connected to a Pharmacia FPLC system was used for size-exclusion chromatography; a calibration curve was produced with protein standards used previously (LydakisSimantiris et al. 1999b). The column was equili-

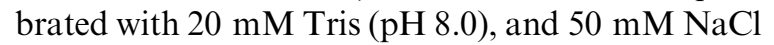
was used, instead of $150 \mathrm{mM} \mathrm{NaCl}$, which was necessary to prevent C28A,C51A MSP from aggregating on the gel filtration column.

\section{Results}

C28A,C51A MSP reconstitutes $\mathrm{O}_{2}$ evolution activity after exposure to high temperatures

Previously, it was shown that C28A,C51A MSP is more difficult to manipulate during purification; urea must be included in buffers to prevent the mutant protein from clogging ion exchange chromatography columns (Betts et al. 1996). This protein is nevertheless capable of rebinding to USW-PS II preparations and of reconstituting $\mathrm{O}_{2}$ evolution activities (Betts et al. 1996). To determine whether the presence of the disulfide bridge in WT MSP was critical for MSP thermostability, C28A,C51A MSP was incubated at $25{ }^{\circ} \mathrm{C}$, or at $90{ }^{\circ} \mathrm{C}$ followed by cooling to $25^{\circ} \mathrm{C}$, and both samples were then assayed for their ability to reconstitute $\mathrm{O}_{2}$ evolution. As can be seen in Figure 1a, unheated C28A,C51A MSP restored $\mathrm{O}_{2}$ rates and yields up to $35-45 \%$ of SW-PS II control levels upon rebinding of about 2 moles C28A,C51 A MSP $/ \mathrm{mol}$ PS II. These activities were unchanged when additional MSP was added to the reconstitution mixtures. Binding of C28A,C51A MSP to USW-PS II preparations, however, failed to saturate at any protein concentration tested, whereas WT MSP binding to PS II saturates at about 2 moles MSP/mol PS II (Betts et al. 1994). The adventitious binding exhibited by C28A,C51A MSP is probably due to non-specific binding by the mutant protein to USW-PS II samples. This binding behavior has been previously detected with other MSP mutants from both eukaryotic and prokaryotic sources (Popelkova et al. 2002a, b; Motoki et al. 2002; Popelkova et al. 2003a). Non-specific MSP binding was confirmed by incubating C28A,C51A MSP with intact PS II samples (which have native WT MSP bound with high affinity to the specific MSP binding sites), as previously described (data not shown) (Popelkova et al. 2002a, b, 2003a) Following incubation, the PS II samples were washed to remove any weakly bound C28A,C51A MSP. With no specific binding sites available, C28A,C51A MSP should only be able to bind non-specifically to these PS II samples. It was found that incubation of 0-2 moles of C28A,C51A MSP per mol intact PS II produced no detectable non-specific binding, but incubation of 4 moles of C28A,C51A MSP per mol intact PS II resulted in non-specific binding of about 1 mol of C28A,C51A MSP per mol intact PS II. Incubation of 8 moles of C28A,C51A MSP per mol intact PS II produced a non-specific binding of about 2 moles of C28A,C51A MSP per mol intact PS II (data not shown).

Figure $1 \mathrm{~b}$ presents data on the reconstitution of $\mathrm{O}_{2}$ evolution activity by C28A,C51A MSP that was 


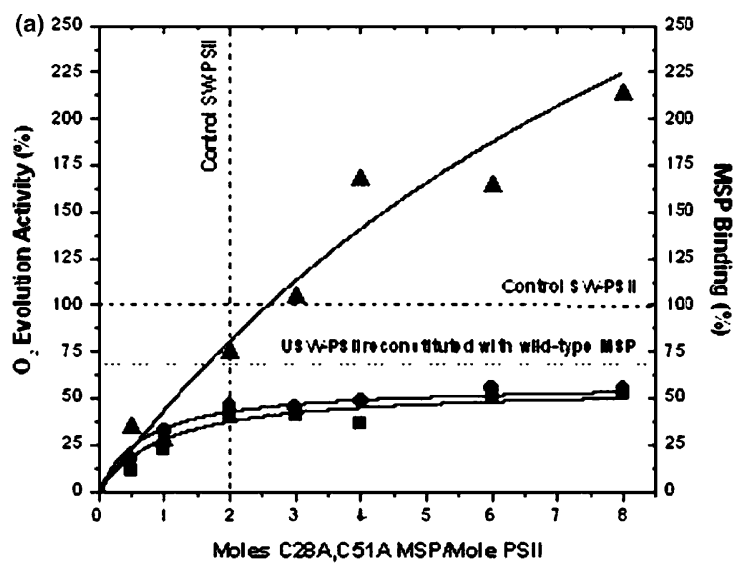

(b)

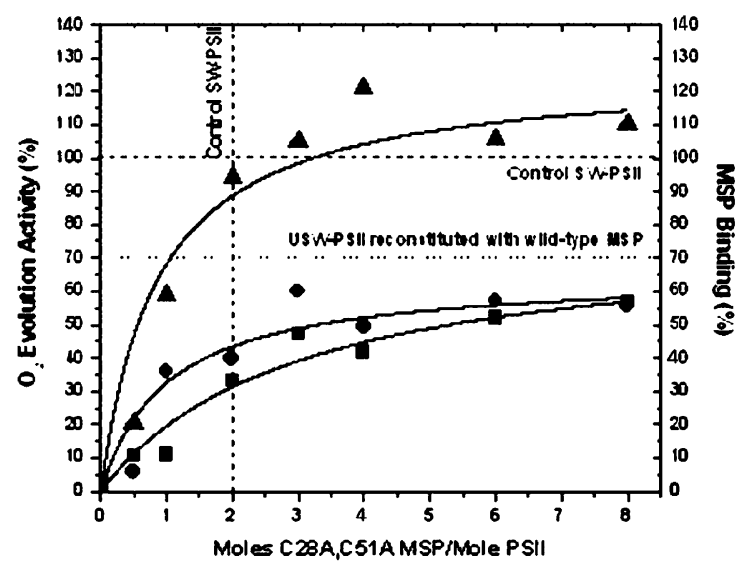

Figure 1. Reconstitution of USW-PS II preparations with recombinant C28A,C51A MSP. C28A,C51A MSP was incubated for $20 \mathrm{~min}$ at room temperature (a) or $90{ }^{\circ} \mathrm{C}$ (b) prior to addition to the USW-PS II samples. MSP binding curves are represented by $(\boldsymbol{\Delta})$. The $\mathrm{O}_{2}$ rates $(\boldsymbol{O})$ and $\mathrm{O}_{2}$ yields $(\boldsymbol{\square})$ were obtained from assays carried out under continuous illumination for 1 or $4 \mathrm{~min}$., respectively. Reconstitution mixtures were incubated on ice for $60 \mathrm{~min}$ and then assayed for $\mathrm{O}_{2}$ evolution activity. Residual activity from USW-PS II preparations was subtracted from the reconstituted samples, and control $(100 \%$ activity) was that of SW-PS II samples. The dotted lines indicate WT MSP activity levels, while the dashed lines represent WT MSP binding levels (Betts et al. 1996a; Popelkova et al. 2003a).

incubated at $90{ }^{\circ} \mathrm{C}$, and then cooled prior to use. Approximately $50 \%$ of the C28A,C51A MSP initially in solution forms insoluble aggregates upon heating under the conditions used here (a detailed characterization of MSP aggregation is given in Wyman and Yocum 2005). After cooling to $25^{\circ} \mathrm{C}$, the sample was centrifuged to remove aggregated protein and the supernatant was used for the rebinding experiments, as described in Materials and methods section. Reconstitution of $\mathrm{O}_{2}$ rates and $\mathrm{O}_{2}$ yields by the heated, soluble MSP fraction attained
$30-35 \%$ the SW-PS II control levels at about 2 moles of C28A,C51A MSP per mol PS II, and ultimately reached a plateau at 6 moles of C28A,C51A MSP per mol PS II, with $\mathrm{O}_{2}$ rates and $\mathrm{O}_{2}$ yields of $50 \%$ of $\mathrm{SW}-\mathrm{PS}$ II values. Comparison of these results with those in Figure 1a reveals that binding of the heated C28A,C51A MSP to USWPS II parallels recovery of $\mathrm{O}_{2}$ evolution activity, but non-specific binding of heated C28A,C51A MSP was not observed.

The activity of the heat-aggregated MSP was also characterized. In its aggregated form, C28A,C51A MSP was unable to reconstitute $\mathrm{O}_{2}$ evolution activity upon incubation with USWPS II (data not shown). However, when the aggregated protein was solubilized as described in Materials and methods section and used in reconstitution assays, $\mathrm{O}_{2}$ rates and yields were obtained that saturated at about 2 moles C28A,C51A MSP $/ \mathrm{mol}$ PS II, yielding $25 \%$ and $55 \%$ of the SW-PS II control $\mathrm{O}_{2}$ rates and $\mathrm{O}_{2}$ yields, respectively (Figure 2). The solubilized protein rebinds to USW-PS II to about $80 \%$ of SW-PS II control levels in incubation mixtures containing 2 moles of C28A,C51A MSP per mol PS II. At 3-6 moles of C28A,C51A MSP per mol PS II, the solubilized protein bound at levels comparable to the WT MSP content of SW-PS II. However, upon incubation of USW-PS II with 8 moles of solubilized C28A,C51A MSP per mol PS II, both specific and non-specific binding were observed; about 2 moles of solubilized

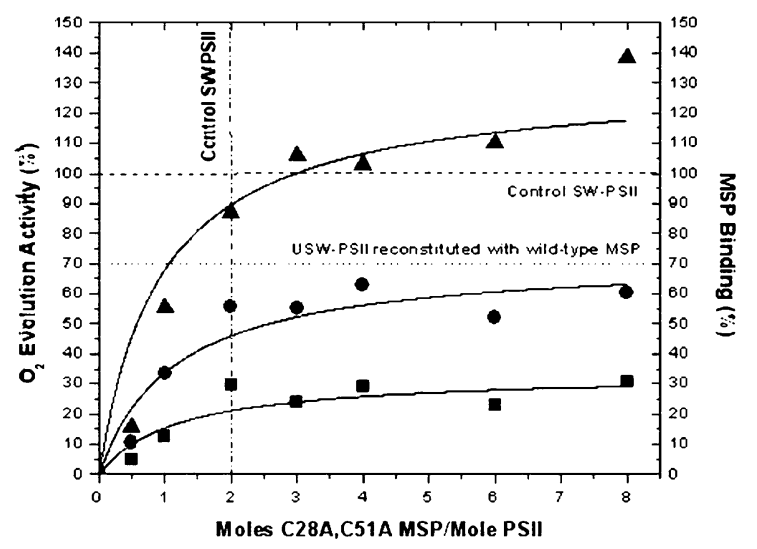

Figure 2. Reconstitution of USW-PS II preparations with resolubilized recombinant C28A,C51A MSP. Heat aggregated C28A,C51A MSP renatured and incubated for $20 \mathrm{~min}$ at room temperature prior to use in $\mathrm{O}_{2}$ evolution assays. Other conditions are given in the legend of Figure 1. 
C28A,C51A MSP per mol PS II bound specifically, and about 1 mole of C28A,C51A MSP per mol PS II was non-specifically bound (Figure 2). Thus, the ability of C28A,C51A MSP to bind nonspecifically to PS II preparations appears to be decreased upon heating. The origin of this behavior is unknown, although it might, in theory, be due to an altered MSP solution conformation induced by the heating and cooling steps. It is clear that C28A,C51A MSP is thermostable, as shown by the results in Figures 1 and 2, retaining its activity even after exposure to high temperatures for an extended period of time, or after aggregation during heating. This behavior is comparable to the thermostability reported for WT MSP (Lydakis-Simantiris et al. 1999b). WT MSP at sufficiently high concentrations also aggregated upon heating (Wyman and Yocum 2005). The $\mathrm{O}_{2}$ evolution activity and binding levels of WT MSP from the soluble supernatant and the resolubilized aggregated fractions were found to be similar to those produced from the same fractions from C28A,C51A MSP (data not shown).

\section{Solution structure of C28A,C51A MSP}

Further evidence for the thermostability of C28A,C51A MSP was obtained from analyses of the protein's secondary structure using far-UV CD spectroscopy. The far-UV CD spectra shown in Figure 3 were obtained with a C28A,C51A MSP sample that was heated and cooled. Although the $25{ }^{\circ} \mathrm{C}$ far-UV $\mathrm{CD}$ spectrum of C28A,C51A MSP differs from that obtained with WT MSP under similar experimental conditions (Lydakis-Simantiris et al. 1999b), heating and subsequent cooling do not produce drastic changes in the overall appearance of the C28A,C51A MSP spectrum when compared to that of the WT protein. At $25^{\circ} \mathrm{C}, \mathrm{C} 28 \mathrm{~A}, \mathrm{C} 51 \mathrm{~A}$ MSP exhibits a deep trough at $202 \mathrm{~nm}$ (indicative of random coil), and a slight trough between 205-225 nm (associated with the presence of $\alpha$-helix). Upon heating C28A,C51A MSP to $90{ }^{\circ} \mathrm{C}$, the troughs at $202 \mathrm{~nm}$ and $225 \mathrm{~nm}$ deepened, indicating increased levels of both random coil and $\alpha$-helix; cooling to $25^{\circ} \mathrm{C}$ restored a large fraction of the original spectrum, consistent with earlier results obtained with WT MSP (Lydakis-Simantiris et al. 1999b). It should also be noted that the far-UV CD spectrum of unheated $\mathrm{C} 28 \mathrm{~A}, \mathrm{C} 51 \mathrm{~A}$ MSP at $25^{\circ} \mathrm{C}$ shown in Figure 3 is very

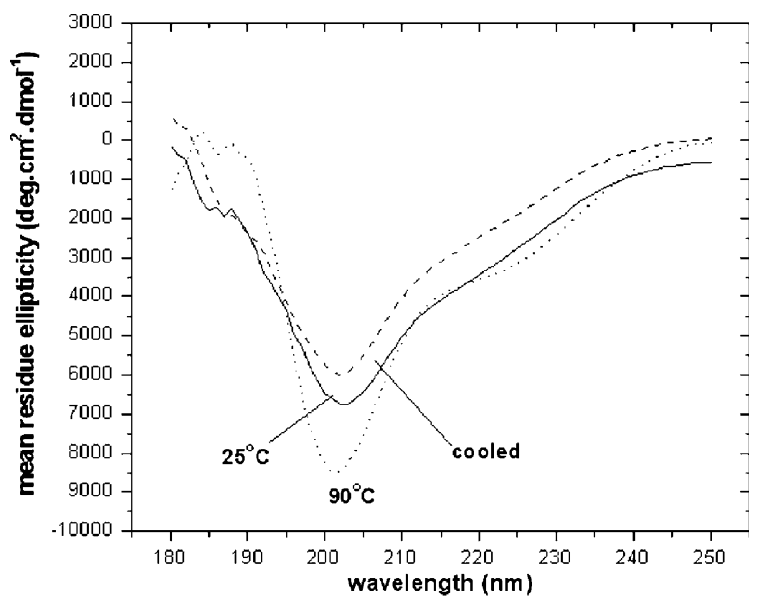

Figure 3. Effect of heating on the far-UV CD spectrum of C28A,C51A MSP. Samples of C28A,C51A MSP $(13.7 \mu \mathrm{M})$ in $10 \mathrm{mM} \mathrm{KH} \mathrm{PO}_{4}$ buffer, $\mathrm{pH} 6.0$ and 5.7 (calculated using the buffer's temperature coefficients at $25^{\circ} \mathrm{C}$ and $90{ }^{\circ} \mathrm{C}$ ) were equilibrated at the indicated temperatures $\left(25^{\circ} \mathrm{C}(-)\right.$, $90^{\circ} \mathrm{C}(\cdots \cdots \cdots)$, cooled to $\left.25^{\circ} \mathrm{C}(-\cdots)\right)$ and 20 scans were averaged at each temperature. Predicted secondary structure compositions for the protein at each temperature are presented in Table 1. Experimental conditions: scan width, 250-180 nm; time constant, $1 \mathrm{~s}$; bandwidth, $1 \mathrm{~nm}$; path length, $1 \mathrm{~mm}$; sample volume, $300 \mu$ l.

similar to the spectrum of WT MSP at $90{ }^{\circ} \mathrm{C}$ (Lydakis-Simantiris et al. 1999b), and agrees well with the far-UV CD spectrum of reduced native WT MSP (Tanaka et al. 1989).

Table 1 presents the calculated $\alpha$-helix, $\beta$-sheet, and random coil contents of C28A,C51A MSP at $25^{\circ} \mathrm{C}$ and $90{ }^{\circ} \mathrm{C}$. These data were obtained from analyses of the C28A,C51A MSP far-UV CD spectra by several computational methods (CONTIL/LL, CDSSTR), which compare the far-UV CD spectra of C28A,C51A MSP to spectra of proteins with known secondary structures, allowing one to estimate the percentage of secondary structures ( $\alpha$-helix, $\beta$-sheet/turn, and random coil) in C28A,C51A MSP (Sreerama and Woody 2000). Of the two groups of protein basis sets available for comparisons, basis sets 6 and 7 are considered to be more suitable for estimations of MSP secondary structure because they contain structural data for five denatured proteins, which are hypothesized to have secondary structural contents more similar to that of intrinsically disordered proteins (Sreerama and Woody 2000). For comparison, CD spectra of WT MSP were also taken at $25^{\circ} \mathrm{C}, 90^{\circ} \mathrm{C}$, and after cooling to $25^{\circ} \mathrm{C}$. The spectra, which were similar to those described 
Table 1. Secondary structure predictions for WT MSP and C28A,C51A MSP based on analyses of far-UV CD spectra

\begin{tabular}{|c|c|c|c|c|c|c|c|c|}
\hline \multirow[t]{2}{*}{ Protein } & \multicolumn{4}{|c|}{ Basis sets $1,3,4,6$, and 7 calculated $\%$ of: } & \multicolumn{4}{|c|}{ Basis sets 6 and 7 only calculated $\%$ of: } \\
\hline & $\alpha$-helix & $\beta$-sheet & Turn + unordered & Total & $\alpha$-helix & $\beta$-sheet & Turn + unordered & Total \\
\hline WT $\left(25^{\circ} \mathrm{C}\right)$ & 7 & 36 & 56 & 99 & 4 & 36 & 60 & 99 \\
\hline WT $\left(90^{\circ} \mathrm{C}\right)$ & 7 & 30 & 62 & 99 & 6 & 25 & 68 & 99 \\
\hline WT (Cooled) & 5 & 37 & 56 & 99 & 3 & 37 & 59 & 99 \\
\hline $\mathrm{C} 28 \mathrm{~A}, \mathrm{C} 51 \mathrm{~A}\left(25^{\circ} \mathrm{C}\right)$ & 5 & 37 & 58 & 100 & 4 & 34 & 63 & 101 \\
\hline $\mathrm{C} 28 \mathrm{~A}, \mathrm{C} 51 \mathrm{~A}\left(90^{\circ} \mathrm{C}\right)$ & 7 & 29 & 63 & 99 & 6 & 28 & 65 & 99 \\
\hline C28A,C51A (Cooled) & 5 & 34 & 60 & 99 & 3 & 31 & 65 & 99 \\
\hline
\end{tabular}

Proteins were assayed in $10 \mathrm{mM} \mathrm{KH}{ }_{2} \mathrm{PO}_{4}$ buffer at $\mathrm{pH} 6.0$ and 5.7 , as calculated from the buffer's temperature coefficients at $25{ }^{\circ} \mathrm{C}$ and $90{ }^{\circ} \mathrm{C}$. For a detailed basis set description, see Sreerama and Woody (2000). The numbers shown are averages of results obtained from the basis sets shown and from both CONTIN/LL and CDSSTR methods.

in Lydakis-Simantiris et al. (1999) (data not shown), were used for the WT secondary structure predictions shown in Table 1. Use of basis sets 6 and 7 indicates that at $25^{\circ} \mathrm{C}, \mathrm{C} 28 \mathrm{~A}, \mathrm{C} 51 \mathrm{~A}$ MSP shows increased levels of random coil and $\alpha$-helix, along with decreased amounts of $\beta$-sheet, when compared to WT MSP. Upon heating to $90{ }^{\circ} \mathrm{C}$, C28A,C51A MSP is predicted to gain random coil and $\alpha$-helix at the expense of $\beta$-sheet; WT MSP at $90{ }^{\circ} \mathrm{C}$ is predicted to contain similar fractions of secondary structure, indicating that the values reported here may represent the maximum extent to which MSP, plus or minus the disulfide bond, can lose secondary structure at $90{ }^{\circ} \mathrm{C}$. After cooling to $25^{\circ} \mathrm{C}, \mathrm{C} 28 \mathrm{~A}, \mathrm{C} 51 \mathrm{~A}$ MSP regains its original secondary structure content. These findings, along with the results of the reconstitution experiments using heated C28A,C51A MSP, indicate that MSP retains its thermostability in the absence of the disulfide bridge.

Analyses of the tertiary structure of C28A,C51A MSP were carried out using nearUV CD spectroscopy and gel filtration chromatography. The intensity of CD signals from aromatic amino acids (Phe, Tyr, Trp) that absorb between 250 and $300 \mathrm{~nm}$ is dependent on the local protein environment; hydrophobicity produces stronger signals, while increased hydrophilicity leads to weaker signals (Kelly and Price 1997). Because there are 13 Phe and 8 Tyr residues distributed throughout the MSP sequence, monitoring their near-UV CD signals provides a useful indicator of structural changes in the protein (Tanaka et al. 1989; Shutova et al. 1997; Lydakis-Simantiris et al. 1999a, b; Motoki et al. 2002; Popelkova et al. 2002a, b, 2003a; Wyman and Yocum 2005). The lone Trp residue, located at position 241 near the C-terminus of the MSP primary amino acid sequence, produces an intense near-UV CD signal that has been used to follow changes in this domain's solution structure (Lydakis-Simantiris et al. 1999a, b; Yu et al. 2001; Motoki et al. 2002; Popelkova et al. 2002a, b, 2003a). For WT MSP, the large, welldefined peaks at $292 \mathrm{~nm}$ and $285 \mathrm{~nm}$ shown in Figure 4 have been attributed to Trp and Tyr residues, respectively, while two smaller, broad peaks at 258 and $264 \mathrm{~nm}$ are assigned to Phe (Kelly and Price 1997; Shutova et al. 1997; Lydakis-Simantiris et al. 1999a, b; Motoki et al. 2002; Popelkova et al. 2002a, b, 2003a). As shown in Figure 4, no signals from the Trp or Tyr residues are observed in the near-UV CD spectrum obtained from C28A,C51A MSP; the only signals present are weak Phe peaks centered at $258 \mathrm{~nm}$ and $264 \mathrm{~nm}$. In good agreement with these findings, reduced native WT MSP was found to produce a very similar near-UV CD spectrum (Tanaka et al. 1989). An earlier nearUV CD spectrum for C28A,C51A MSP showed two small, broad peaks at 264 and $272 \mathrm{~nm}$ (Popelkova et al. 2003b). It appears that those signals were due to noise; a higher concentration of C28A,C51A MSP was used to obtain the nearUV CD spectrum presented in Figure 4, and this resulted in improved signal to noise ratio and more clearly defined peaks for Phe. These data suggest that the structure of C28A,C51A MSP has been modified so that the protein environments containing the Trp and Tyr residue(s) responsible for the near-UV CD signals seen in the WT MSP spectrum at $25^{\circ} \mathrm{C}$ have been shifted 


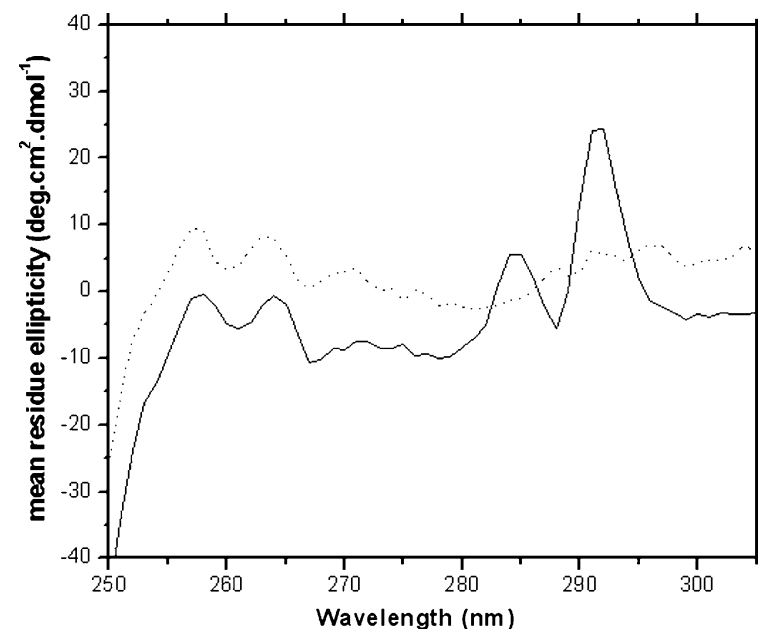

Figure 4. Near-UV CD spectra of WT MSP and C28A,C51A MSP. Near-UV CD spectra were recorded after allowing WT MSP (-) and C28A,C51A MSP (.......) to equilibrate to $25^{\circ} \mathrm{C}$. Each spectrum is the average of 20 scans. The protein concentrations were $50.5 \mu \mathrm{M}$ (WT MSP) and $28.1 \mu \mathrm{M}$ (C28A,C51A MSP). The buffer in both experiments was $10 \mathrm{mM}$ $\mathrm{KH}_{2} \mathrm{PO}_{4}$, pH 6.0. Experimental conditions: scan width, 320$250 \mathrm{~nm}$; time constant, 1s; bandwidth, $1 \mathrm{~nm}$; path length, $1 \mathrm{~cm}$; sample volume, $1 \mathrm{ml}$.

from hydrophobic to more solvent-exposed domains, resulting in a loss of signal from these aromatic residues. Wild-type MSP heated to $90{ }^{\circ} \mathrm{C}$ produces a similar near-UV CD spectrum to that of C28A,C51A MSP at $25^{\circ} \mathrm{C}$ (LydakisSimantiris et al. 1999b; Popelkova et al. 2003b; data not shown). In this case, the loss of signals from the Trp and Tyr are proposed to arise from increased disorder caused by the elevated temperature.

Further evidence that C28A,C51A MSP is more disordered in solution than WT MSP is evident in a comparison of the UV absorption spectra of these proteins. The intensity of UV absorption by aromatic amino acids in proteins depends on the environment surrounding them (Schmid 1997). Aromatic amino acids in regions of greater hydrophobicity exhibit increased absorption; conversely, when exposed to the solvent, signals from these residues are blue-shifted (Schmid 1997). As shown in Figure 5, WT MSP exhibits a characteristic, well-defined shoulder at $293 \mathrm{~nm}$ from Trp (Schmid 1997). This shoulder is absent from the C28A,C51A MSP UV spectrum (Figure 5), indicating that loss of the disulfide bridge shifts this residue to a more solvent exposed environment.

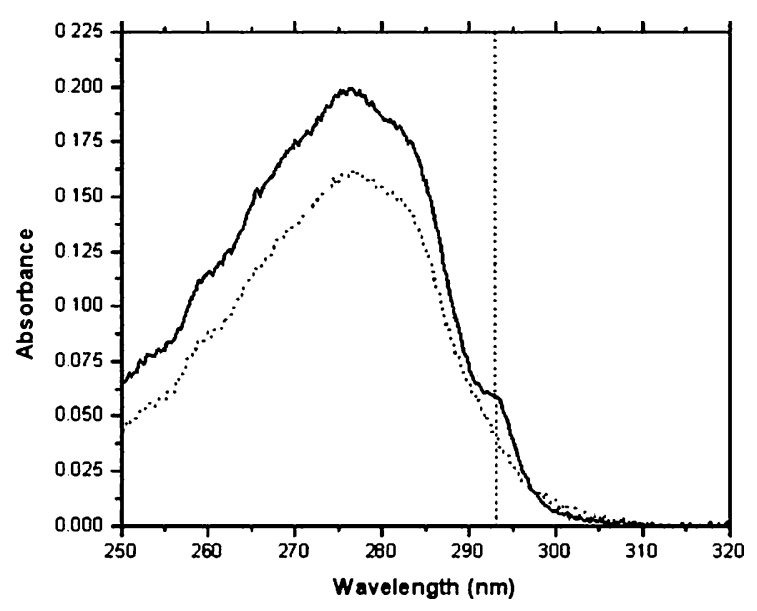

Figure 5. UV absorption spectra of WT MSP and C28A,C51A MSP. The protein concentrations were $12.9 \mu \mathrm{M}$ (WT MSP, $(-))$ and $10.6 \mu \mathrm{M}(\mathrm{C} 28 \mathrm{~A}, \mathrm{C} 51 \mathrm{~A} \mathrm{MSP},(\ldots \ldots))$. Both proteins were dissolved in $10 \mathrm{mM} \mathrm{KH}_{2} \mathrm{PO}_{4}$, pH 6.0 buffer. Experimental conditions: scan width, $320-250 \mathrm{~nm}$; temperature, $25^{\circ} \mathrm{C}$; path length, $1 \mathrm{~cm}$; sample volume, $1 \mathrm{ml}$. The vertical dotted line denotes $293 \mathrm{~nm}$, the position of the shoulder assigned to Trp.

One of the key characteristics of intrinsically disordered proteins is their anomalously large apparent molecular masses (Weinreb et al. 1996; Lydakis-Simantiris et al. 1999; Uversky, 2002a, b). While the $p s b O$ gene sequence predicts a molecular mass of 26,540 Da for WT MSP (Tyagi et al. 1987), SDS-PAGE gives apparent molecular mass of $33 \mathrm{kDa}$ (Kuwabara and $\mathrm{Mu}-$ rata, 1979), and an even larger value (38-41 kDa (Lydakis-Simantiris et al. 1999; Popelkova et al. 2002a, b, 2003a)) is obtained with gel filtration chromatography. The mutant has a predicted molecular mass of $26,476 \mathrm{Da}$ due to replacements of Cys by Ala residues. This was confirmed by MALDI-TOF mass spectroscopy (data not shown). The electrophoretic mobility of the double mutant protein was consistent with a molecular mass of $33 \mathrm{kDa}$ on SDS-PAGE gel electrophoresis (Betts et al. 1996). However, characterization of C28A,C51A MSP by sizeexclusion chromatography gave the results presented in Table 2. The double mutant protein exhibits an apparent molecular mass of about $51 \mathrm{kDa}$, which is larger than WT MSP and some $\mathrm{N}$-terminal MSP mutants (Popelkova et al. 2002a, b, 2003a), and which approaches the molecular masses of some C-terminal truncation mutants of MSP (Lydakis-Simantiris et al. 1999a). 
Table 2. Apparent molecular masses of WT and mutants of MSP based on size exclusion chromatography

\begin{tabular}{lll}
\hline Protein & $\begin{array}{l}\text { Apparent } \\
\text { molecular } \\
\text { mass (kDa) }\end{array}$ & Reference \\
& 38 & This work \\
WT & 34 & Popelkova et al. 2003a \\
$\Delta$ T7M & 33 & Popelkova et al. 2003a \\
$\Delta$ T15M & 41 & Lydakis-Simantiris et al. 1999a \\
E246K & 51 & This work \\
C28A,C51A & 52 & Lydakis-Simantiris et al. 1999a \\
L245@ & 62 & Lydakis-Simantiris et al. 1999a \\
L245E & & \\
\hline
\end{tabular}

\section{Discussion}

Intrinsically disordered, or natively unfolded proteins as they are also called, are characterized by smaller than usual amounts of estimated secondary structure, abnormally high estimated molecular masses determined by several techniques (gel filtration, SDS-PAGE, analytical ultracentrifugation), and by a thermostability that is unusual for proteins derived from mesophiles (Weinreb et al. 1996; Dunker et al. 2001; Uversky 2002b). From the available high resolution structural information on these proteins, it appears that in some cases such proteins possess regions of ordered secondary and tertiary structure as well as domains that are disordered (Dunker et al. 2001). The basis for classification of MSP as either an intrinsically disordered protein or as a molten globule is described in Lydakis-Simantiris et al. (1999b) and Shutova et al. (2000), respectively. A significant factor in designating MSP as a molten globule in solution was that its heat resistance or thermostability, could, in theory, be explained by the presence of the disulfide bridge, which was hypothesized to stabilize a hydrophobic core of $\beta$-sheet structure (Shutova et al. 2000). Thermostability can be conferred on proteins by the introduction of non-native disulfide bridges, as, for example, in the cases of T4 lysozyme (containing no native disulfide bridges) (Perry and Wetzel 1984; Matsumura et al. 1989), ribonuclease $\mathrm{H}$, whose $\mathrm{C}$-terminal region (residues $88-155$ ) is intrinsically disordered (Kanaya et al. 1991), and xylanase (Wakarchuk et al. 1994). This increased thermostability is hypothesized to be due to decreased conformational entropy in these pro- teins' peptide backbones that is caused by the new disulfide bridges (Matsumura et al. 1989). However, introduction of disulfide bridges does not always lead to increased protein thermostability, as in the case of addition of disulfide bridges to dihydrofolate reductase (Villafranca et al. 1987) or subtilisin BPN' (Mitchinson and Wells 1989).

Although thermostability is a property of intrinsically disordered proteins, the possibility that the disulfide bridge stabilizes MSP against thermal denaturation, as proposed by Shutova et al. (2000), could not be ruled out. Experiments with C28A,C51A MSP show that the unheated protein rebinds to USW-PS II preparations and catalyzes $\mathrm{O}_{2}$ evolution activity as reported previously (Betts et al. 1996); however, in our assays, it exhibited both specific and non-specific binding, a behavior that was not seen previously and is probably a consequence of using higher concentrations of the protein in the new reconstitution experiments. When the thermostability of C28A,C51A MSP was tested at $90^{\circ} \mathrm{C}$, the mutant was found to aggregate upon heating, a behavior also detected in native WT MSP when the disulfide bridge was chemically reduced (Tanaka and Wada 1988; Tanaka et al. 1989), and during the purification of C28A,C51A MSP (Betts et al. 1996). However, heated C28A,C51A MSP from both the supernatant fraction and the urea-solubilized aggregated material were reconstitutively active (Figures 1 and 2).

Far-UV CD spectroscopic analysis was used to probe the effects of heating on the secondary structure of C28A,C51A MSP. At high temperature, C28A,C51A MSP showed a loss of $\beta$-sheet with modest gains in $\alpha$-helix and disorder in its secondary structure; however, upon cooling, it regained a substantial portion of its original secondary structure, a behavior also seen in the farUV CD spectrum of WT MSP upon heating and cooling (Figure 3; Table 1; Lydakis-Simantiris et al.1999b; data not shown). Another characteristic of intrinsically disordered proteins is their extended conformations in solution, which is evidenced by their anomalous mobilities in gel filtration analyses (Weinreb et al. 1996; LydakisSimantiris et al. 1999b; Uversky et al. 2000; Dunker et al. 2001; Uversky 2002a, b). While Betts et al. (1996) found that the molecular mass of C28A,C51A MSP was $33 \mathrm{kDa}$ on SDS-PAGE, the gel filtration analyses reported here indicate that it 
has an apparent molecular mass of $51 \mathrm{kDa}$, greater than the value found for WT MSP, and closer in size to some MSP C-terminal mutants (Table 2; Lydakis-Simantiris et al. 1999a, b; Popelkova et al. 2003b). Additional data on the disordered state of C28A,C51A MSP is provided by its near-UV CD and UV absorbance spectra. The well-defined near-UV CD signals from the Trp and Tyr residues, seen in WT MSP, are absent in C28A,C51A MSP, suggesting that these residues (and the domains in which they are located) have been shifted from hydrophobic environments to more hydrophilic surroundings (Figure 4). The UV absorbance spectrum of C28A,C51A MSP, showing a loss of the distinctive Trp shoulder seen at $293 \mathrm{~nm}$ in WT MSP, is consistent with exposure of this residue to a more hydrophilic environment (Figure 5).

It is apparent that the presence of an intact disulfide bridge in MSP is necessary for the protein's proper solution structure, most importantly for a hydrophobic C-terminal domain in the vicinity of $\operatorname{Trp} 241$. However, MSP retains its thermostable behavior in the absence of these structural features. It has been shown by isotope editing FT-IR spectroscopy that MSP gains $\beta$-sheet at the expense of random coil upon binding to PS II (Hutchison et al. 1998). This finding is supported by a crystal structure of PS II, which indicates that PS II-bound MSP is elongated and contains large amounts of $\beta$-sheet (Ferreira et al. 2004). Because C28A,C51A MSP retains its ability to bind specifically to PS II and reconstitute $\mathrm{O}_{2}$ evolution activity, the presence of a stabilizing disulfide bridge within a hydrophobic core of $\beta$-sheet structure in WT MSP does not appear to be necessary for MSP function. These observations also demonstrate that the thermostability of MSP is not dependent on the presence of the disulfide bond to maintain a specific hydrophobic core of $\beta$-sheet structure. This would suggest that the solution structure of MSP is probably not related to that of molten globules.

It is interesting to note that C28A,C51A MSP, whose mutations reside near the $\mathrm{N}$-terminus of the protein, has characteristics similar to those of C-terminal MSP mutants; non-specific binding to USW-PS II samples, increased apparent molecular size by gel filtration, and some loss of $\beta$-sheet structure in favor of random coil (Betts et al. 1998;
Lydakis-Simantiris et al. 1999a, b; Popelkova et al. 2003b). As outlined in Popelkova et al. (2003b), these similarities support the hypothesis of Enami et al. (1998) that there is an interaction between the MSP N- and C-termini in solution, based on the finding that the zero-length, watersoluble cross-linker carbodiimide EDC catalyzed bond formation between a MSP C-terminal residue (E246) to a residue (K48) present in the disulfide loop. In addition, several $\mathrm{N}$-terminal MSP truncation mutants produced by Popelkova et al. (2002a, 2002b, 2003a) also exhibited properties in solution similar to those of C28A,C51A MSP and the MSP C-terminal mutants, suggesting that the disulfide bridge and loop and MSP C-terminus are also in proximity to the MSP $\mathrm{N}$-terminus. These findings were used to generate models for the solution structures of WT MSP and C28A,C51A MSP (Popelkova et al. 2003b).

It has been hypothesized that of the eight Tyr residues present in MSP, only one (Y242), which is highly conserved in all known MSP sequences (De Las Rivas and Heredia 1999; Motoki et al. 2002), is responsible for the near-UV CD Tyr signal detected in WT MSP (Shutova et al. 1997; Motoki et al. 2002; Popelkova et al. 2003a, b). This hypothesis is supported by our finding that although there are a number of Tyr and Phe residues distributed throughout the primary sequence of MSP, only Phe signals are detected in the C28A,C51A MSP near-UV CD spectrum (Figure 4). The absence of Trp and Tyr signals suggests that the environment around W241 and Y242 in C28A,C51A MSP has become more hydrophilic. This is consistent with the report of Zhang et al. (2005) who have shown that one Tyr in MSP is resistant to modification by $\mathrm{N}$-acetylimidazole unless the protein is first unfolded in $8 \mathrm{M}$ urea.

Uversky et al. (2000) have shown that a defining property of intrinsically disordered proteins is the ratio of charged to hydrophobic residues in their primary amino acid sequences. They postulated that these proteins' high ratios of charged to hydrophobic residues resulted in a lack of regular structure (due to internal charge repulsions) that lead to their thermostability, because these proteins are able to undergo changes in solution structure in a more energetically favorable manner upon exposure to extreme changes in temperature. With an appropriate balance of charged to 
hydrophobic residues in their sequences, intrinsically disordered proteins can maintain an equilibrium between the forces of charge repulsion (which favor protein unfolding/disorder), and forces that drive protein folding (hydrophobic interactions). Dunker et al. (2001) have proposed that certain amino acids facilitate protein folding, while others create disorder, based on the relative frequencies of amino acids found in ordered and disordered domains of proteins having determined structures. Using these criteria, amino acids were characterized as 'order-promoting' (W, C, F, I, Y, V, L, N), 'neutral' (having no affect on structure formation) (H, T, M, D), or 'disorder-promoting' (A, R, G, Q, $\mathrm{S}, \mathrm{P}, \mathrm{E}, \mathrm{K})$. The percentages of these types of amino acids were determined for the primary sequences of two intrinsically disordered proteins (WT MSP, NACP) and a molten globule protein (human carbonic anhydrase B, according to Shutova et al. (2000)) (Popelkova et al. 2003b). The intrinsically disordered proteins contained higher amounts of disorder-promoting amino acids (55.5 and $60.8 \%$, respectively) and lower levels of order-promoting residues (30.3 and $24.3 \%$ ), than did carbonic anhydrase B, a "normally folded' protein which possessed increased amounts of order-promoting amino acids (34.7\%) and decreased levels of disorder-promoting residues $(48.3 \%)$. These calculations suggest that MSP contains greater levels of intrinsic disorder than does a protein selected as a model for molten globule behavior in solution.

While this research, and that of Betts et al. (1996), show that the presence of the disulfide bridge is unnecessary for MSP to effectively restore $\mathrm{O}_{2}$ evolution activity in vitro, it is important to note that it has also been shown that the disulfide bridge must remain intact in vivo in order for MSP to function (Burnap et al. 1994). The highly conserved residue C20 (identical to C28 in spinach MSP) of the cyanobacterium Synechocystis sp. PCC6803 was mutated into a Ser, which eliminates the disulfide bond that normally formed with $\mathrm{C} 45$ (C51 in spinach). Synechocystis carrying the C20S mutation accumulated normal levels of MSP mRNA, but failed to accumulate the protein, and as a result exhibited $\mathrm{O}_{2}$ evolution rates similar to those of the Synechocystis $\triangle p s b O$ mutation. From these findings, the authors concluded that while the lack of a disulfide bridge did not affect the stability of MSP mRNA, it did render the gene product subject to increased rates of protein degradation within the cell because MSP could not fold and bind properly to PS II.

\section{Acknowledgement}

This research was supported by a Grant to CFY from the NSF Molecular Biochemistry Program (MCB 0110455).

\section{References}

Ahmed A, Tajmirriahi HA and Carpentier R (1995) A quantitative secondary structure-analysis of the $33-\mathrm{kDa}$ extrinsic polypeptide of Photosystem-II by FTIR spectroscopy. FEBS Lett 363: 65-68

Berthold DA, Babcock GT and Yocum CF (1981) A highly resolved, oxygen-evolving Photosystem-II preparation from spinach thylakoid membranes - electron-paramagnetic-resonance and electron-transport properties. FEBS Lett 134: 231-234

Betts SD, Hachigian TM, Pichersky E and Yocum CF (1994) Reconstitution of the spinach oxygen-evolving complex with recombinant Arabidopsis manganese-stabilizing protein. Plant Mol Biol 26: 117-130

Betts SD, Ross JR, Hall KU, Pichersky E and Yocum CF (1996) Functional reconstitution of Photosystem II with recombinant manganese-stabilizing proteins containing mutations that remove the disulfide bridge. Biochim Biophys Acta 1274: 135-142

Betts SD, Lydakis-Simantiris N, Ross JR and Yocum CF (1998) The carboxyl-terminal tripeptide of the manganesestabilizing protein is required for quantitative assembly into Photosystem II and for high rates of oxygen evolution activity. Biochemistry 37: 14230-14236

Bricker TM (1992) Oxygen evolution in the absence of the 33-kilodalton manganese-stabilizing protein. Biochemistry 31: 4623-4628

Bricker TM and Frankel LK (1998) The structure and function of the $33 \mathrm{kDa}$ extrinsic protein of Photosystem II: a critical assessment. Photosynth Res 56: 157-173

Burnap RL, Qian M, Shen JR, Inoue Y and Sherman LA (1994) Role of disulfide linkage and putative intermolecular binding residues in the stability and binding of the extrinsic manganese-stabilizing protein to the Photosystem-II reaction-center. Biochemistry 33: 13712-13718

Debus RJ (1992) The manganese and calcium ions of photosynthetic oxygen evolution. Biochim Biophys Acta 1102: 269-352

De Las Rivas J and Heredia P (1999) Structural predictions on the $33 \mathrm{kDa}$ extrinsic protein associated to the oxygen evolving complex of photosynthetic organisms. Photosyn Res 61: 11-21

Dunker AK, Lawson JD, Brown CJ, Williams RM, Romero P, Oh JS, Oldfield CJ, Campen AM, Ratliff CR, Hipps KW, Ausio J, Nissen MS, Reeves R, Kang CH, Kissinger CR, Bailey RW, Griswold MD, Chiu M, Garner EC and Obradovic Z (2001) Intrinsically disordered protein. J Mol Graph Model 19: 26-59 
Enami I, Kamo M, Ohta H, Takahashi S, Miura T, Kusayanagi M, Tanabe S, Kamei A, Motoki A, Hirano M, Tomo T and Satoh K (1998) Intramolecular cross-linking of the extrinsic 33-kDa protein leads to loss of oxygen evolution but not its ability of binding to Photosystem II and stabilization of the manganese cluster. J Biol Chem 273: 4629-4634

Ferreira KN, Iverson TM, Maghlaoui K, Barber J and Iwata S (2004) Architecture of the photosynthetic oxygen-evolving center. Science 303: 1831-1838

Ghanotakis DF, Topper JN, Babcock GT and Yocum CF (1984) Water-soluble $17-\mathrm{kDa}$ and $23-\mathrm{kDa}$ polypeptides restore oxygen evolution activity by creating a high-affinity binding site for $\mathrm{Ca}^{2+}$ on the oxidizing side of Photosystem II. FEBS Lett 170: 169-173

Hutchison RS, Betts SD, Yocum CF and Barry BA (1998) Conformational changes in the extrinsic manganese stabilizing protein can occur upon binding to the Photosystem II reaction center: an isotope editing and FT-IR study. Biochemistry 37 : $5643-5653$

Ikeuchi M and Inoue Y (1988) A new $4.8 \mathrm{kDa}$ polypeptide intrinsic to the PS II reaction center, as revealed by modified SDS-PAGE with improved resolution of low molecular weight proteins. Plant Cell Physiol 29: 1233-1239

Johnson WC (1990) Protein secondary structure and circular dichroism - a practical guide. Proteins-Struct Funct Genet 7: 205-214

Kamiya N and Shen JR (2003) Crystal structure of oxygenevolving Photosystem II from Thermosynechococcus vulcanus at 3.7-angstrom resolution. Proc Natl Acad Sci USA 100: 98-103

Kanaya S, Katsudanakai C and Ikehara M (1991) Importance of the positive charge cluster in Escherichia coli ribonuclease HI for the effective binding of the substrate. J Biol Chem 266: $11621-11627$

Kelly SM and Price NC (1997) The application of circular dichroism to studies of protein folding and unfolding. Biochim Biophys Acta 1338: 161-185

Kok B, Forbush B and Mcgloin M (1970) Cooperation of charges in photosynthetic $\mathrm{O}_{2}$ evolution-I. A linear four step mechanism. Photochem Photobiol 11: 457-475

Kuwabara T and Murata N (1979) Purification and characterization of 33 kilodalton protein of spinach chloroplasts. Biochim Biophys Acta 581: 228-236

Loll B, Gerold G, Slowik D, Voelter W, Jung C, Saenger W and Irrgang K-D (2005) Thermostability and $\mathrm{Ca}^{2+}$ binding properties of wild type and heterologously expressed PsbO protein from cyanobacterial Photosystem II. Biochemistry 44: 4691-4698

Lydakis-Simantiris N, Betts SD and Yocum CF (1999a) Leucine 245 is a critical residue for folding and function of the manganese-stabilizing protein of Photosystem II. Biochemistry 38: 15528-15535

Lydakis-Simantiris N, Hutchison RS, Betts SD, Barry BA and Yocum CF (1999b) Manganese stabilizing protein of Photosystem II is a thermostable, intrinsically disordered polypeptide. Biochemistry 38: 404-414

Matsumura M, Becktel WJ, Levitt M and Matthews BW (1989) Stabilization of phage-T4 lysozyme by engineered disulfide bonds. Proc Natl Acad Sci USA 86: 6562-6566

Mitchinson C and Wells JA (1989) Protein engineering of disulfide bonds in subtilisin BPN'. Biochemistry 28: 4807-4815

Miyao M and Murata N (1984) Role of the 33-kDa polypeptide in preserving $\mathrm{Mn}$ in the photosynthetic oxygen evolution system and its replacement by chloride ions. FEBS Lett 170 : $350-354$
Miyao M, Murata N, Lavorel J, Maisonpeteri B, Boussac A and Etienne AL (1987) Effect of the 33-kDa protein on the S-state transitions in photosynthetic oxygen evolution. Biochim Biophys Acta 890: 151-159

Motoki A, Usui M, Shimazu T, Hirano M and Katoh S (2002) A domain of the manganese-stabilizing protein from Synechococcus elongatus involved in functional binding to Photosystem II. J Biol Chem 277: 14747-14756

Nowaczyk M, Berghaus C, Stoll R and Rogner M (2004) Preliminary structural characterization of the $33 \mathrm{kDa}$ protein (PsbO) in solution studied by site-directed mutagenesis and NMR spectroscopy. Phys Chem Chem Phys 6: 48784881

Ono TA and Inoue Y (1983) Mn-preserving extraction of 33$\mathrm{kDa}, 24-\mathrm{kDa}$ and $16-\mathrm{kDa}$ proteins from $\mathrm{O}_{2}$-evolving PS-II particles by divalent salt-washing. FEBS Lett 164: 255-260

Ono T and Inoue Y (1986) Effects of removal and reconstitution of the extrinsic 33-kDa, 24-kDa and 16-kDa proteins on flash oxygen yield in Photosystem II particles. Biochim Biophys Acta 850: 380-389

Perry LJ and Wetzel R (1984) Disulfide bond engineered into T4 lysozyme - stabilization of the protein toward thermal inactivation. Science 226: 555-557

Popelkova H, Im MM, D’Auria J, Betts SD, Lydakis-Simantiris N and Yocum CF (2002a) N-terminus of the Photosystem II manganese stabilizing protein: effects of sequence elongation and truncation. Biochemistry 41: 2702-2711

Popelkova H, Im MM and Yocum CF (2002b) N-terminal truncations of manganese- stabilizing protein identify two amino acid sequences required for binding of the eukaryotic protein to Photosystem II and reveal the absence of one binding-related sequence in cyanobacteria. Biochemistry 41 : 10038-10045

Popelkova H, Im MM and Yocum CF (2003a) Binding of manganese stabilizing protein to Photosystem II: identification of essential N-terminal threonine residues and domains that prevent nonspecific binding. Biochemistry 42: 6193-6200

Popelkova H, Wyman A and Yocum C (2003b) Amino acid sequences and solution structures of manganese stabilizing protein that affect reconstitution of Photosystem II activity. Photosynth Res 77: 21-34

Schmid FX (1997) Optical spectroscopy to characterize protein conformation and conformational changes. In: Creighton TE (ed) Protein Structure: a Practical Approach, pp 261-297. IRL Press, New York

Seidler A (1996) The extrinsic polypeptides of Photosystem II. Biochim Biophys Acta 1277: 35-60

Shen JR and Inoue Y (1993) Binding and functional properties of 2 new extrinsic components, cytochrome $c 550$ and a $12-\mathrm{kDa}$ protein, in cyanobacterial Photosystem-II. Biochemistry 32: 1825-1832

Shen JR, Qian M, Inoue Y and Burnap RL (1998) Functional characterization of Synechocystis sp. PCC 6803 delta psbU and delta psbV mutants reveals important roles of cytochrome $c$-550 in cyanobacterial oxygen evolution. Biochemistry 37 : $1551-1558$

Shutova T, Irrgang KD, Klimov VV and Renger G (2000) Is the manganese stabilizing $33 \mathrm{kDa}$ protein of Photosystem II attaining a 'intrinsically disordered' or 'molten globule' structure in solution? FEBS Lett 467: 137-140

Shutova T, Irrgang KD, Shubin V, Klimov VV and Renger G (1997) Analysis of pH-induced structural changes of the isolated extrinsic 33-kilodalton protein of Photosystem II. Biochemistry 36: 6350-6358 
Sonoyama M, Motoki A, Okamoto G, Hirano M, Ishida H and Katoh S (1996) Secondary structure and thermostability of the Photosystem II manganese-stabilizing protein of the thermophilic cyanobacterium Synechococcus elongatus. Biochim Biophys Acta 1297: 167-170

Sreerama N and Woody RW (2000) Estimation of protein secondary structure from circular dichroism spectra: comparison of CONTIN, SELCON, and CDSSTR methods with an expanded reference set. Anal Biochem 287: 252-260

Svensson B, Tiede DM and Barry BA (2002) Small-angle X-ray scattering studies of the manganese stabilizing subunit in Photosystem II. J Phys Chem B 106: 8485-8488

Tanaka S, Kawata Y, Wada K and Hamaguchi K (1989) Extrinsic 33-kilodalton protein of spinach oxygen-evolving complexes - kinetic studies of folding and disulfide reduction. Biochemistry 28: 7188-7193

Tanaka S and Wada K (1988) The status of cysteine residues in the extrinsic 33-kDa protein of spinach Photosystem II complexes. Photosynth Res 17: 255-266

Tyagi A, Hermans J, Steppuhn J, Jansson C, Vater F and Herrmann RG (1987) Nucleotide sequence of cDNA clones encoding the complete $33 \mathrm{kDa}$ precursor protein associated with the photosynthetic oxygen evolving complex from spinach. Mol Gen Genet 207: 288-293

Uversky VN (2002a) Intrinsically disordered proteins: a point where biology waits for physics. Prtn Sci 11: 739-756

Uversky VN (2002b) What does it mean to be natively unfolded? Eur J Biochem 269: 2-12

Uversky VN, Gillespie JR and Fink AL (2000) Why are "natively unfolded" proteins unstructured under physiologic conditions? Proteins-Struct Funct Genet 41: 415-427

Villafranca JE, Howell EE, Oatley SJ, Xuong NH and Kraut J (1987) An engineered disulfide bond in dihydrofolate reductase. Biochemistry 26: 2182-2189

Wakarchuk WW, Sung WL, Campbell RL, Cunningham A, Watson DC and Yaguchi M (1994) Thermostabilization of the Bacillus circulans xylanase by the introduction of disulfide bonds. Protein Eng 7: 1379-1386
Weinreb PH, Zhen WG, Poon AW, Conway KA and Lansbury PT (1996) NACP, a protein implicated in Alzheimer's disease and learning, is natively unfolded. Biochemistry 35: 13709-13715

Wyman AJ and Yocum CF (2005) Assembly and function of the Photosystem II manganese-stabilizing protein: lessons from its natively unfolded behavior. Photosyn Res (in press)

$\mathrm{Xu}$ Q and Bricker TM (1992) Structural organization of proteins on the oxidizing side of Photosystem II - 2 molecules of the $33-\mathrm{kDa}$ manganese stabilizing protein per reaction center. J Biol Chem 267: 25816-25821

Xu Q, Nelson J and Bricker TM (1994) Secondary structure of the $33 \mathrm{kDa}$, extrinsic protein of Photosystem II - a far-UV circular dichroism study. Biochim Biophys Acta 1188: 427431

Yu Y, Li R, Xu CH, Ruan KC, Shen YK and Govindjee (2001) N-bromosuccinimide modification of tryptophan 241 at the C-terminus of the manganese-stabilizing protein of plant Photosystem II influences its structure and function. Physiol Plant 111: 108-115

Zhang F, Gao J, Weng J, Tan C, Ruan K, Xu C and Jiang D (2005) Structural and functional differentiation of three groups of tyrosine residues by acetylation of $N$-acetylimidazole in manganese stabilizing protein. Biochemistry 44: 719725

Zhang LX, Liang HG, Wang J, Li WR and Yu TZ (1996) Fluorescence and Fourier transform infrared spectroscopic studies on the role of disulfide bond in the calcium binding in the $33 \mathrm{kDa}$ protein of Photosystem II. Photosynth Res 48: 379-384

Zouni A, Witt HT, Kern J, Fromme P, Krauss N, Saenger W and Orth P (2001) Crystal structure of Photosystem II from Synechococcus elongatus at 3.8-angstrom resolution. Nature 409: 739-743

Zubrzycki IZ, Frankel LK, Russo PS and Bricker TM (1998) Hydrodynamic studies on the manganese-stabilizing protein of Photosystem II. Biochemistry 37: 13553-13558 